TRABAJO Y TRABAJADORES:

RED LATINOAMERICANA

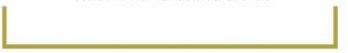

\title{
Responsabilidad empresarial en la última dictadura argentina: aportes a partir de casos de empresas agroindustriales en las regiones Noroeste y Noreste (1974-1983)
}

\author{
VICTORIA BASUALDO
}

Consejo Nacional de Investigaciones Científicas y Técnicas Facultad Latinoamericana de Ciencias Sociales basuvic@yahoo.com.ar

\author{
MARÍA ALEJANDRA ESPONDA
}

Universidad Nacional Arturo Jauretche

Facultad Latinoamericana de Ciencias Sociales aleesponda@gmail.com

\section{SILVIA NASSIF}

Consejo Nacional de Investigaciones Científicas y Técnicas Facultad Latinoamericana de Ciencias Sociales nassifsilvia@gmail.com

\begin{abstract}
Resumen: Este artículo analiza procesos de investigación y judicialización de casos de responsabilidad empresarial en delitos de lesa humanidad durante la última dictadura en Argentina (1976-1983). En particular, estudia cuatro casos de empresas agroindustriales: dos ingenios azucareros ubicados en las provincias de Tucumán (ingenios La Fronterita y Concepción) y otro en Jujuy (ingenio Ledesma), y una empresa yerbatera y de producción de té en la provincia de Corrientes (Las Marías). El artículo subraya que todos estos casos incluyen no solo trabajo fabril sino también rural, caracterizado por una mayor precarización de las relaciones laborales y una mayor explotación. Se
\end{abstract}


enfatizan las potencialidades de estos estudios, pero también los obstáculos y limitaciones de estos procesos de Memoria, Verdad y Justicia debido al fuerte poder empresarial y las dificultades de la organización obrera y sindical.

Palabras clave: dictadura argentina (1976-1983), actividades agroindustriales, responsabilidad empresarial, delitos de lesa humanidad, proceso de Memoria Verdad y Justicia

Recibido: 1 de marzo de 2021. Aprobado: 10 de mayo de 2021. 
Este artículo se propone transmitir algunos avances recientes en los procesos de investigación y judicialización de casos de responsabilidad empresarial en delitos de lesa humanidad durante la última dictadura en Argentina (19761983). Desde la transición democrática se inició un proceso de justicia con avances y retrocesos significativos. Inicialmente, a partir de la importante tarea de la Comisión Nacional sobre la Desaparición de Personas (Conadep), y luego en el juicio a las Juntas en 1985, pudieron ser analizadas y luego juzgadas las responsabilidades militares y especialmente los integrantes de las Juntas gobernantes. Sin embargo, con la sanción de las leyes Punto Final en 1986 y Obediencia Debida en 1987; y años más tarde con los decretos de indultos entre 1989 y 1990, la posibilidad de justicia quedó anulada. Ante la imposibilidad de llevar adelante procesos de judicialización penal, en 1998 los llamados "Juicios por la Verdad" permitieron que cientos de familiares y víctimas directas pudieran dar testimonio y ejercieran su derecho a la verdad. En 2005, finalmente, la Corte Suprema de Justicia ratificó la anulación de las leyes de Obediencia Debida y Punto Final, conocidas como las "leyes de la impunidad”, y se pudo reiniciar un proceso de justicia que derivó, hasta la actualidad, en la condena de 1025 imputados por crímenes de lesa humanidad. ${ }^{1}$

En los últimos años, y gracias a la gran cantidad de testimonios e investigaciones en curso, se ha ampliado la posibilidad de imputación de otros sectores no militares (la jerarquía eclesiástica, así como figuras del poder judicial y muy especialmente del sector empresarial, entre otros) que participaron activamente en la comisión de delitos de lesa humanidad o que, al menos, requieren ser investigados. En ese marco, la relación entre investigación académica y judicialización se ha mostrado sumamente fructífera. Importantes investigaciones han hecho foco en las transformaciones estructurales, otras en los circuitos represivos y las fuerzas actuantes, en el análisis de las personas y colectivos víctimas directas, en las organizaciones de derechos humanos y sus luchas, así como en el papel de sectores civiles. Esta vinculación se expresó también, por ejemplo, en la convocatoria a diversos científicos de un conjunto de disciplinas a declarar en los tribunales como "testigos de contexto". ${ }^{2}$

1 Según informó en marzo de 2021 la Procuraduría de Crímenes contra la Humanidad. Disponible en https://www.fiscales.gob.ar/lesa-humanidad/?tipoentrada=estadisticas (Consultado el 24 de mayo de 2021).

2 Los "testigos de contexto" son expertos convocados a exponer, en el marco judicial, evidencias científicas o académicas vinculadas con procesos de importancia para comprender los hechos analizados en las causas, y para proveer herramientas archivísticas, documentales o conceptuales. Para profundizar en estas líneas ver, por ejemplo, Gabriela Águila, "La dictadura militar argentina: interpretaciones, problemas y debates", en Revista Páginas, 1, 1, 2008; Horacio Verbitsky y Juan Pablo Bohoslavsky, Cuentas pendientes. Los 
Sin embargo, a pesar de que muchos testimonios de trabajadores desde el comienzo de la democracia daban cuenta de diversas formas de participación, directa e indirecta, de los empresarios y funcionarios en la represión hacia ellos y sus familias, durante décadas resultó difícil avanzar en la investigación judicial sobre las poblaciones obreras y la responsabilidad de los empresarios, presente en diversos documentos en los que quedó registrado su accionar represivo durante el terrorismo de Estado. Aunque a partir de la reapertura de los juicios desde 2005 se lograron pasos importantes en este sentido, considerados extraordinarios a nivel internacional -como la condena en 2016 del empresario Marcos Levín, dueño de la empresa La Veloz del Norte (condena luego anulada en 2017) y la condena de dos altos funcionarios empresariales de Ford Motor Argentina en 2018 considerándolos partícipes necesarios de las violaciones a los derechos humanos de 24 ex trabajadores y delegados de la empresa entre 1976 y 1977- resta aún poder avanzar en una gran cantidad de casos. Es particularmente urgente poder lograr progresos en lo que refiere a trabajadores de zonas y actividades rurales, que se encuentran en posiciones muy relegadas y complejas.

En particular, este trabajo se propone compartir algunas reflexiones y avances en un conjunto de casos de empresas agroindustriales abordando tres casos de ingenios azucareros ubicados en las provincias de Tucumán y Jujuy, y un caso de una empresa yerbatera y de producción de té en la provincia de Corrientes. Se eligieron especialmente estos casos debido a que se trata de actividades que integran el trabajo industrial y el trabajo rural en el norte argentino y que han utilizado históricamente fuerza de trabajo en condiciones de explotación extrema, llegando en algunos casos al trabajo esclavo o semiesclavo. Por otro lado, gran parte de la población reclutada pertenece a pueblos originarios, cuyos territorios ancestrales les han sido expropiados en el avance territorial de los poderes económicos sobre todo a partir de la segunda mitad del siglo XIX. ${ }^{3}$ Asimismo, en la región nordeste argentina, una parte importante de la fuerza de trabajo se asentó en colonias de diferentes nacionalidades, especialmente europeas, formadas al calor de las políticas inmigratorias de fines del siglo XIX. ${ }^{4}$ La posibilidad de centrar el análisis en estos casos tiene el objetivo de discernir las potencialidades de analizarlos en conjunto, no solo para poder echar luz sobre aspectos en común

cómplices económicos de la dictadura (Buenos Aires: Siglo XXI Editores, 2013); María José Sarrabayrouse y Santiago Garaño “Aportes de la antropología política y jurídica al campo de los estudios sobre memoria y del pasado reciente", Cuadernos de Humanidades, 30 (2019): 44-63.

3 Hugo Trinchero, Los dominios del demonio. Civilización y barbarie en las fronteras de la Nación. El Chaco Central (Buenos Aires: Eudeba, 2000).

4. Leopoldo Bartolomé, Los colonos de Apóstoles. Estrategias adaptativas y etnicidad en una colonia eslava en Misiones (Posadas: Editorial Universitaria de Misiones, 2000). 
sino también para poder dar cuenta de los obstáculos y limitaciones de los procesos de Memoria, Verdad y Justicia en estos territorios y poblados pequeños, que en muchos casos mantienen múltiples características de dominación económica, territorial y social de antaño.

Se parte aquí de los hallazgos de un proceso de investigación, del que formaron parte las autoras, llevado adelante por cuatro instituciones: el Área de Economía y Tecnología de FLACSO, el Centro de Estudios Legales y Sociales (CELS), la Secretaría de Derechos Humanos y el Programa Verdad y Justicia, plasmado en el libro Responsabilidad empresarial en delitos de lesa humanidad. Represión a trabajadores durante el terrorismo de Estado (2015). Estos casos han sido profundizados a partir de avances recientes y de la participación directa de las autoras, de diversas maneras, en los procesos judiciales acontecidos con posterioridad a aquellas primeras investigaciones. Nuevos testimonios y documentos de archivo han fortalecido las investigaciones iniciales.

En síntesis, el foco específico de este artículo en los procesos de responsabilidad empresarial en delitos de lesa humanidad en el marco de actividades agroindustriales permite profundizar una serie de dimensiones que han sido poco analizadas en el caso argentino. La represión sobre colectivos obreros que incluyen trabajadores/as de fábrica y rurales debe analizarse en el marco de relaciones laborales diversas con niveles altos de precarización, obstáculos para la organización sindical, estrategias empresariales específicas vinculadas al control sobre el territorio y en relación con las estructuras de poder político militar. Todas estas características tuvieron impacto e incidencia en la posibilidad de las propias poblaciones de visibilizar sus dolorosas experiencias, en las dificultades de los procesos de investigación y en la forma en la que se desarrollaron los procesos de Memoria, Verdad y Justicia.

En primer lugar se abordarán los casos de dos ingenios azucareros localizados en la provincia de Tucumán: La Fronterita, en el suroeste de la provincia, y Concepción, a pocos kilómetros de la capital. Se trata de una provincia en la que la agroindustria azucarera era -y continúa siendo- la principal actividad económica generadora de puestos de trabajo. Durante la dictadura autodenominada "Revolución Argentina" (1966-1973), se aplicaron políticas regresivas que significaron una crisis económica y social de proporciones, con la eliminación de 11 de los 27 ingenios existentes hasta ese momento y la mitad de los empleos en la actividad azucarera -de 100.000 puestos de trabajo se pasó a 50.000 aproximadamente-, junto a la profundización de la concentración monopólica de la producción en manos de pocos ingenios, como en los casos de ambas empresas. En ese contexto, los trabajadores organizados en la Federación Obrera Tucumana de la Industria Azucarera (FOTIA) ofrecieron resistencia. 
A principio de los años setenta, los sindicatos obreros de La Fronterita y Concepción se encontraban dirigidos por sectores combativos y los obreros fueron protagonistas de diferentes acciones de luchas en defensa de los puestos de trabajo y por mejores condiciones laborales. En febrero de 1975, en un ambiente complejo, Tucumán sufrió el despliegue de las fuerzas de seguridad a partir del "Operativo Independencia" a través del decreto $\mathrm{N}$. 216/75 del Poder Ejecutivo Nacional, que tenía el objetivo de eliminar toda actividad considerada "subversiva" e implicó una política represiva extrema sobre la población. Entre otras acciones, se emplazó un Centro Clandestino de Detención (CCD) en la propiedad privada del ingenio La Fronterita. La existencia de este CCD fue registrada en 1984, apenas finalizó la dictadura, en el informe de la Conadep. Casi cuarenta años después de estos sucesos, se inició una causa judicial en la que se investigan los hechos ocurridos en La Fronterita. Con distintos avances y retrocesos, el proceso continúa abierto.

En segundo lugar, se analizará el caso del ingenio Ledesma, en la provincia de Jujuy. Se trata de una empresa de gran relevancia provincial y nacional que comenzó como un ingenio azucarero y fue expandiendo sus actividades económicas. Desde fines de los años sesenta, pero fundamentalmente a partir de comienzos de los setenta, los trabajadores del ingenio lograron la conducción del sindicato y tejieron una alianza social que a nivel local y provincial cambió la relación de fuerzas respecto del papel dominante que había tenido históricamente la empresa Ledesma sobre el territorio y las relaciones económicas, laborales y políticas. En respuesta a las exigencias de cambios en las condiciones de vida y de trabajo, y su adaptación a las ordenanzas locales y leyes provinciales y nacionales, se desató a partir de 1974 un proceso represivo de gran alcance contra los trabajadores/as, sus allegados, los abogados laboralistas y los políticos de la zona que habían desafiado a la empresa, la cual proveyó recursos logísticos y materiales para el desarrollo del proceso represivo. A pesar de que se trata de un caso tempranamente denunciado y documentado en el marco de la Conadep y el juicio a las Juntas de 1985, el proceso de justicia ha enfrentado numerosos obstáculos que muestran el peso de los actores económicos y su capacidad de condicionar los procesos de judicialización y rendición de cuentas.

En tercer lugar, se abordará el caso de la empresa "Las Marías", dedicada a la producción de yerba mate y té en la provincia de Corrientes, propiedad de una familia fundadora de la localidad de Virasoro, donde comenzó a operar en la década de 1920. La expansión de su poderío no solo se debió a la explotación extrema de la fuerza de trabajo y diversas estrategias empresariales, sino al constante emparentamiento de sus dueños con el poder político, fenómeno que se expresó en la participación de su referente principal, Adolfo Navajas Artaza, en las dictaduras de 1955, 1966 y finalmente en la última dictadura. A principios de los años setenta, los 
trabajadores del establecimiento, tanto los que trabajaban en el proceso industrial como quienes lo hacían en los campos y montes, lograron nuclearse y emprender acciones sindicales en demanda de derechos laborales básicos. A partir de 1976, los trabajadores sindicalizados y sus familias sufrieron una fuerte represión con participación de las estructuras empresariales. El proceso de justicia ha enfrentado múltiples dificultades debidas a la fuerte incidencia territorial, política y económica de la familia, que se expresaron en 2018 en la absolución del único imputado. Pese a esto, en la actualidad se está llevando a cabo una nueva causa contra el dueño de la empresa, de 93 años de edad.

Para cerrar, se compartirán algunas conclusiones que permitirán reflexionar tanto sobre los avances de los procesos de investigación y judicialización como sobre las dificultades y obstáculos. Aunque parte de ellos pueden explicarse en función de las dificultades que presenta la problemática de la responsabilidad empresarial, se analizarán además las características específicas que presentan estas actividades agroindustriales y el particular peso e incidencia de estas grandes empresas en los territorios en los que están emplazadas.

\section{Los casos de los ingenios azucareros La Fronterita y Concepción, provincia de Tucumán}

La agroindustria azucarera ha sido históricamente una actividad económica clave de la región del noroeste argentino, que comprende las provincias de Jujuy, Salta, Tucumán, Catamarca, La Rioja y Santiago del Estero. Dado que se trata de una actividad agroindustrial, participan en ella distintos tipos de trabajadores vinculados, por un lado, al tipo de tarea que realizan (fábrica o campo) y, por otro, al tiempo de contratación de modo permanente o temporario, es decir lo que durase la cosecha. Durante el tiempo de zafra, entre mayo y noviembre generalmente, se contrata a un mayor número de trabajadores.

Con el propósito de comprender más cabalmente el análisis de los casos de los ingenios tucumanos, resulta necesario tener presente el proceso abierto a mediados de los años sesenta con la instauración de la dictadura de la "Revolución Argentina", que realizó en Tucumán un proceso de profunda reestructuración, presentado como "racionalización" económica en la agroindustria azucarera. En una provincia en la que, desde fines del siglo XIX, el azúcar era la actividad más importante, esta política significó la agudización de una crisis económica y social sin precedentes, con el cierre de 11 de los 27 ingenios azucareros existentes, la eliminación de más de 50.000 puestos de trabajo, la migración forzada de más de un cuarto de los habitantes, el empobrecimiento de los pequeños y medianos productores 
cañeros, entre otros sectores sociales, junto a un proceso de concentración monopólica de la producción azucarera. Frente a este proceso, los trabajadores azucareros nucleados en la Federación Obrera Tucumana de la Industria Azucarera (FOTIA) ofrecieron resistencia junto a otros sectores sociales, entre los que se destacó el movimiento estudiantil. Estos hechos de gran convulsión social se enmarcaron en un proceso más amplio de activismo y radicalización obrera en distintos puntos del país, la región y el mundo. ${ }^{5}$

Un año antes del golpe de Estado de marzo de 1976, la provincia de Tucumán sufrió el despliegue de las Fuerzas Armadas a partir del Decreto N. ${ }^{\circ}$ 261/75 firmado por el Poder Ejecutivo Nacional en febrero de 1975, que dio inicio al "Operativo Independencia”. ${ }^{6}$ Ello implicó un fuerte proceso represivo en la provincia que también resulta necesario tener presente al momento de analizar los casos de los ingenios investigados.

\section{La Fronterita y Concepción: conflictividad obrera y concentración de la producción}

Para el análisis de la responsabilidad empresarial en delitos de lesa humanidad en la provincia de Tucumán nos centramos en la investigación de dos ingenios azucareros, Concepción y La Fronterita. La presencia de ambas empresas era de larga data en las comunidades en las que se hallaban insertas, generando un extenso dominio sobre el territorio laboral. Ambas firmas no solo eran propietarias de las fábricas correspondientes, sino que también poseían importantes extensiones de tierra que ocupaban en las plantaciones de caña de azúcar.

La Compañía Azucarera Concepción, asociada a la familia Paz, fue la firma propietaria del ingenio Concepción entre los años 1974 y 1983. Esta fábrica está ubicada en la Banda del Río Salí a 5 kilómetros de la capital de la provincia, y era y continúa siendo la más importante en cuanto a los niveles de molienda. Por su parte, el ingenio La Fronterita se encuentra ubicado a 45 kilómetros de San Miguel de Tucumán, en el actual departamento de

5 Sobre el proceso de cierre de ingenios azucareros y resistencia obrera ver Roberto Pucci, Historia de la destrucción de una provincia. Tucumán 1966 (Buenos Aires: Pago Chico, 2007); Silvia Nassif, Tucumán en llamas: El cierre de ingenios y las luchas obreras contra la dictadura (1966-1973) (Tucumán: UNT, 2016).

6 En cuanto al Operativo Independencia consultar Santiago Garaño, "El Operativo Independencia (Tucumán, 1975-1977). Una experiencia fundacional del "terrorismo de Estado", en Prácticas genocidas y violencia estatal en perspectiva transdisciplinar, coord. J. Lanata, (Bariloche: IIDyPCa-CONICET, 2014), 2-17; también Ana Jemio, El Operativo Independencia en el sur tucumano (1975-1976). Las formas de la violencia estatal en los inicios del genocidio (Tesis de doctorado, Facultad de Ciencias Sociales, Buenos Aires: 2019). 
Famaillá y desde 1923 hasta 2016 fue propiedad de la sociedad José Minetti \& Cía.

En ambos casos se verifica que, en los años previos a la dictadura iniciada en 1976, los obreros azucareros se encontraban en un proceso activo de militancia sobrellevando distintos conflictos con las empresas por mejores salarios y condiciones de trabajo. El descabezamiento de las comisiones directivas y cuerpos de delegados en los ingenios permitió a las Fuerzas Armadas y a los sectores empresariales imponer cambios significativos en las relaciones laborales y productivas, en línea con lo que venían buscando desde los años sesenta. En el ingenio Concepción se había producido una reorganización del sindicato bajo la dirección de una comisión directiva combativa en 1973, que contaba además con un poderoso cuerpo de delegados que se distinguía por la significativa cantidad de representantes, su organización y la participación de distintas corrientes políticas. Estas formas les posibilitaron a los obreros de fábrica y de surco protagonizar importantes luchas, en las que ocuparon en distintas oportunidades el ingenio entre 1966 y 1974, y llegaron a paralizar la molienda obteniendo aumentos salariales y mejoras en las condiciones de trabajo.

En el ingenio La Fronterita, a principios de los años setenta, el sindicato de obreros de fábrica y de surco del ingenio atravesaba un proceso de recuperación sindical bajo la dirección de sectores combativos. En ambos casos, las comisiones directivas y los cuerpos de delegados fueron descabezados mediante la represión. Las transformaciones de ambos ingenios en el período dictatorial no se restringieron al desmantelamiento de la organización sindical en ambas plantas y la imposición de dinámicas de disciplinamiento laboral y terror, sino que también incluyeron significativos beneficios a ambas empresas durante este período. Ello ocurrió en especial en el ingenio Concepción, que fue el de mayor crecimiento a nivel nacional durante el período y llegó a producir, al final de la dictadura, un 42 \% más de lo que había producido en 1976, pero con menos de la mitad de sus trabajadores.

Por su parte, el ingenio La Fronterita también se benefició durante la última dictadura, aumentando su producción en un 30,7\%. Asimismo, el grupo Minetti se apoderó del ingenio Bella Vista en 1979. Este ingenio, junto a otros, había pertenecido a la empresa estatal CONASA (Compañía Nacional Azucarera SA), que fue desguazada y rematada en este período. Los cambios producidos en el empleo también fueron significativos en La Fronterita, con un importante descenso de la mano de obra empleada, en especial entre los obreros que realizaban trabajo en los surcos. También se profundizó la tendencia de despoblamiento y desarme de las colonias del ingenio. Ello estaba relacionado con la tecnificación producida en el campo, precisamente 
uno de los puntos por los que habían peleado los obreros azucareros durante la huelga obrera de $1974 .^{7}$

\section{Responsabilidad empresarial en delitos de lesa humanidad cometidos contra trabajadores de los ingenios La Fronterita y Concepción ${ }^{8}$}

De acuerdo con cifras al momento de la publicación del Informe de responsabilidad empresarial en 2015, 51 trabajadores fueron víctimas del terrorismo de Estado en los ingenios tucumanos de La Fronterita y Concepción. De ellos, 17 fueron detenidos y luego liberados (33\%), 30 fueron detenidos y desaparecidos (59\%), mientras que 4 fueron asesinados (8\%). Los datos muestran que casi la mitad del total de las víctimas obreras de estos dos ingenios habían tenido una participación sindical. En ambos casos fueron secuestradas la plana mayor de las comisiones directivas -secretarios generales y adjuntos, junto a otros integrantes del gremio-, lo que muestra claramente la política de descabezamiento de los sindicatos. Precisamente estos gremios habían cumplido un rol activo en la huelga obrera azucarera de septiembre de 1974 .

En el propio establecimiento laboral de La Fronterita ocurrió el hecho más extremo de militarización del territorio, cuando la empresa cedió parte de su propiedad privada a las Fuerzas Armadas para su utilización como centro clandestino de detención, donde se produjeron violaciones extremas a los derechos humanos. Ello quedó documentado hace más de treinta años en el informe de la Conadep en 1984 y también en el de la Comisión Bicameral

7 En plena cosecha, los trabajadores paralizaron por más de dos semanas los trapiches y suspendieron el envío de caña, ocasionando pérdidas significativas a los empresarios. La Federación exigía la reapertura de los ingenios cerrados; rechazaba la mecanización integral de la zafra hasta que no se garantizara la creación de nuevos puestos de trabajo, exigiendo que cada mil surcos de caña se empleasen a un obrero y medio; y peleaba por la defensa de la Compañía Nacional Azucarera S.A. (CONASA), entre otros reclamos.

8 Para la realización de este punto nos basamos en los informes de los ingenios La Fronterita y Concepción publicados en AEyT de FLACSO, CELS, PVJ y SDH, Responsabilidad empresarial en delitos de lesa humanidad. Represión a trabajadores durante el terrorismo de estado (Buenos Aires: Infojus, 2015); Silvia Nassif, "Terrorismo de Estado en la Argentina: Tucumán y la ofensiva contra los obreros de la agroindustria azucarera”, Revista Interdisciplinaria de Estudios Agrarios, 48 (2018): 57-91; y Victoria Basualdo y Silvia Nassif, "Responsabilidad empresarial en delitos de lesa humanidad: Los casos de los ingenios azucareros Concepción y La Fronterita en Tucumán”, en Operativo Independencia: Geografías, actores y tramas. Tucumán, coords. Ana Bocanegra y Santiago Garaño, (EDUNT, en prensa). 
Investigadora de las Violaciones de los Derechos Humanos en la provincia de Tucumán.

En Tucumán, algunas de las sedes sindicales fueron utilizadas como centros clandestinos de detención, como lo muestra el caso del edificio del sindicato del ingenio Concepción que fue dispuesto por los militares como lugar de detención y de tortura, además de como espacio de oficina. Esto implica que los espacios que habían sido centros de coordinación de la protesta y movilización obrera pasaron a ser utilizados como recintos de represión y disciplinamiento de los trabajadores, llegando a utilizar sus camionetas como vehículos para la represión.

De las víctimas del ingenio Concepción, el 50 \% fueron secuestradas adentro del establecimiento laboral de la empresa, en las "colonias" creadas para explotar las tierras de propiedad de las empresas azucareras. También se produjeron secuestros de obreros de las colonias del ingenio La Fronterita y en la puerta de la fábrica. Se registró además una política de despidos selectivos y/o retiros forzosos de víctimas, que apareció de modo frecuente acompañando la política de secuestro de trabajadores.

Por otra parte, en el caso del ingenio La Fronterita se registraron pedidos de secuestro de trabajadores por parte de la misma empresa, como quedó demostrado en el caso de uno de los dirigentes del sindicato que fue secuestrado en marzo de 1976 y luego liberado. Tiempo después, este trabajador declaró que en las sesiones de tortura uno de sus captores le señaló que ellos sabían que él no tenía nada que ver con la guerrilla y que era solo un dirigente gremial azucarero, advirtiéndole: "ahora te tenés que dar cuenta de cómo viene la mano, a vos te mandan en cana tus patrones". ${ }^{9}$

Además, personal de la empresa La Fronterita brindó información precisa a los militares respecto a los trabajadores y sus actividades gremiales. En ese sentido, un extrabajador señaló lo siguiente:

...la empresa estaba al servicio de los militares dando información al respecto, había personas del ingenio que daban esta información (...), porque los militares no sabían a donde llegar, torturaban a la gente sin saber si tenían relación con algún político o gremialista, pero no tenían la certeza. Los dueños de la empresa son conocedores de todo lo que pasó allí, de todo lo que hicieron los militares. Ellos nos acusaban de zurdos, comunistas, socialistas, los grandes capitalistas son así. El Ejército habló con los jefes administrativos de la empresa, para que ellos colaboren con un censo de las personas que vivían en la colonia y decirles quiénes (...) andaban con el sindicato. Veían personas reunidas en reuniones del sindicato y pasaban los

$9 \quad$ AEyT de FLACSO y otros, Responsabilidad empresarial, 93. 
capataces y se fijaban quienes estaban allí y después iban y les avisaban a los militares. ${ }^{10}$

El ingenio La Fronterita también participó en el aprovisionamiento de recursos logísticos de vehículos para que las Fuerzas Armadas pudiesen llevar a cabo tareas represivas en Tucumán. Ello también se puso de manifiesto en el ingenio Concepción, que aportó camionetas para el secuestro y traslado de personas. Asimismo, esta empresa brindó información de inteligencia al Departamento D-2 de Jefatura de Policía a través de su empresa de seguridad privada ECOS S.A.

Debe considerarse además la contribución económica que realizaron ambas empresas azucareras al Fondo Patriótico Azucarero constituido por Antonio Domingo Bussi, cuyos caudales serían destinados "al mejoramiento, refuerzo y equipamiento de los servicios sanitarios, educacionales y de seguridad de la provincia”. El ingenio que más aportó fue Concepción, con una suma importante de entre 700 a 900 mil dólares. Por su parte, La Fronterita otorgó entre 300 y 400 mil dólares. ${ }^{11}$

\section{Avances posteriores}

Estas investigaciones referidas a la responsabilidad empresarial en delitos de lesa humanidad tuvieron consecuencias fuera del ámbito específico de la investigación científica. Por un lado, implicaron la visibilización y en algunos casos recuperación y apertura de archivos, siendo un ejemplo destacado el Archivo Histórico de la Federación Obrera Tucumana de la Industria Azucarera (FOTIA) "Hilda Guerrero de Molina". ${ }^{12}$ Por otro, nutrieron procesos judiciales junto a la confección de un colectivo de víctimas obreras.

Asimismo, el conocimiento acumulado en estas instancias de investigación fue utilizado en procesos de transferencia en el ámbito judicial como prueba por la Fiscalía que interviene en los juicios de lesa humanidad y fue base de declaración como "testigo experto" en 2016 ante el Tribunal Oral en lo Criminal Federal en el juicio sobre el "Operativo Independencia", en el que muchas de las víctimas habían sido obreros azucareros.

10 AEyT de FLACSO y otros, Responsabilidad empresarial, 95.

11 Respecto al Fondo Patriótico Azucarero ver Hernán López Echagüe, El enigma del General Bussi: del Operativo Independencia al Operativo Retorno (Buenos Aires: Sudamericana, 1991).

12 Hilda Guerrero de Molina, peronista y una de las organizadoras de las ollas populares en contra del cierre de ingenios, fue asesinada por la dictadura en enero de 1967 en la localidad de Bella Vista durante el plan de lucha que se encontraba realizando la FOTIA. 
En abril de 2018, la Fiscalía Federal de Tucumán, utilizando el informe como uno de sus insumos para la investigación, solicitó un pedido de detención y de indagación a seis empresarios vinculados al ingenio La Fronterita por el secuestro de 68 personas, siendo muchas de estas víctimas extrabajadores y dirigentes gremiales azucareros. En mayo de 2019, el juez Raúl Daniel Bejas dictaminó la falta de mérito para procesar o sobreseer a los empresarios, dictamen que fue confirmado, en junio de 2020, por la Cámara Federal de Apelaciones de Tucumán. ${ }^{13}$ Sin embargo, la causa judicial tuvo un nuevo giro cuando en diciembre de 2020 la Sala IV de la Cámara Federal de Casación anuló la falta de mérito, dando lugar a las apelaciones realizadas por el Ministerio Público Fiscal y la querella de Andhes, ${ }^{14}$ que representa a la familia del dirigente desaparecido Fidel Jacobo Ortiz. De este modo, el proceso judicial aún continúa abierto.

\section{El caso del ingenio Ledesma, provincia de Jujuy}

La empresa Ledesma SAAI (Sociedad Anónima Agrícola Industrial), más conocida como "Ingenio Ledesma”, es hasta la actualidad una de las empresas agroindustriales de capitales nacionales más importantes del país y de América Latina. Su establecimiento principal se encuentra en la ciudad de Libertador General San Martín, departamento de Ledesma, en Jujuy. En función de su peso económico y político, se la considera un núcleo central del poder provincial y nacional. ${ }^{15}$

El desarrollo de la empresa a lo largo del siglo XX fue acompañado por un proceso de expansión territorial sobre fincas y pequeñas propiedades que fueron incorporadas a su patrimonio. En este marco, pasaron a estar bajo su dominio tierras de poblaciones en las que se producía caña que la misma empresa adquiría y otros bienes agrarios, como cítricos. ${ }^{16}$ Hacia los años sesenta, la empresa se expandió hacia nuevos rubros que integraban la actividad primaria y fabril, sumando al azúcar y los alcoholes la producción

13 En noviembre de 2020 la justicia federal de Tucumán aceptó que la Secretaría de Derechos Humanos de la Nación se constituya como querellante en la causa.

14 Abogados y Abogadas del Noroeste Argentino en Derechos Humanos y Estudios Sociales.

15 AEyT de FLACSO y otros, Responsabilidad empresarial, y Elizabeth Gómez y Gabriela Karasik, "De la acción social transformadora de Ledesma a la represión de los trabajadores. El abordaje antropológico en los juicios de lesa humanidad”, VII Jornadas Santiago Wallace de Investigación en Antropología Social (Buenos Aires, 2013). Disponible en: http://www.aacademica.com/ooo063/470.

16 Ver testimonios de Máximo Arancibia y Donato Garnica en Ricardo Nelli, La injusticia cojuda. Testimonios de los trabajadores del Ingenio Ledesma (Buenos Aires: Puntosur, 1988), 21. 
de papel. Para ello se montó una planta productiva de más de tres hectáreas cubiertas y otras cuatro para depósito del bagazo de la caña de azúcar. ${ }^{17} \mathrm{En}$ pleno proceso de crecimiento, en 1971, Ledesma absorbió a Calilegua SAAIC, que producía caña de azúcar en la localidad aledaña, y en paralelo introdujo nueva maquinaria para la producción agraria. Ello conllevó profundos cambios en los métodos de producción y en las relaciones laborales y sociales, con fuerte ahorro de fuerza de trabajo. La zafra de 1972 se inauguró con la nueva maquinaria de cosecha mecanizada integral. ${ }^{18}$

Tanto durante la dictadura del general Juan Carlos Onganía, iniciada en 1966, como en los años siguientes, Ledesma estuvo a la cabeza del grupo de empresas beneficiadas por las políticas estatales que favorecieron el proceso de concentración y centralización de la economía. En el marco de una estrecha conexión con el poder político y económico a nivel nacional, los más altos funcionarios de la empresa hicieron aportes fundamentales para la elaboración e instrumentación del plan económico que, a partir de marzo de 1976, llevó adelante el ministro de Economía José Alfredo Martínez de Hoz.

Alrededor de los años setenta, el personal ocupado en forma permanente en Ledesma era de aproximadamente 5000 trabajadores, a los que se sumaban los obreros temporarios que llegaban para la época de zafra. ${ }^{19} \mathrm{El}$ hospital, las proveedurías, la farmacia, el club deportivo, el cementerio, entre otras instituciones sociales y estatales, como ocurrió con las fuerzas públicas de orden nacional cuando éstas fueron destinadas a la zona, también dependían directa o indirectamente de la compañía, ya fuera porque se emplazaban en propiedad de la misma o porque recibían de ella su financiamiento. Ledesma tenía además ferrocarriles propios y, hasta 1970 al menos, tenía acceso e intervención en el manejo de la usina con la cual se abastecía de electricidad y daba servicio de luz a la población.

La empresa Ledesma ejercía un fuerte control sobre el territorio y el mercado laboral de la zona, lo que posibilitaba altos niveles de control sobre los trabajadores. ${ }^{20}$ En términos del proceso histórico de organización obrera y

17 Archivo General de la Nación, Archivo Intermedio, Expediente $\mathrm{N}^{\circ}$ 485.686/71, "Papel, Cartón, Químicos y Afines. Fed de Obreros y Empl. de la Ind. Del s/ dictamen sobre aplicación de convenio que corresp. a la empresa Ledesma S.A. Fábrica de Papel y Celulosa de Jujuy”, p. 208, citado en AEyT de FLACSO y otros, Responsabilidad empresarial.

18 Luis Ernesto Vicini y César Luis Vicini, Mecanización del cultivo de caña de azúcar (Tucumán: INTA, 2010), 17.

19 AGN-AI, Exp. No 485.686/71, p. 450, citado en AEyT de FLACSO y otros, Responsabilidad empresarial.

20 José Sergio Leite Lopes caracterizó este tipo de estructura como "sistema de fábrica con villa obrera”, es decir un sistema estructurado en torno a un establecimiento productivo que da origen a un grupo poblacional: "El resultado es un sistema concreto de relaciones sociales, un sistema de dominación 
sindical, cabe destacar que luego de muchas décadas de obstáculos para la organización de los trabajadores/as se logró la fundación, el 26 de junio de 1960, del Sindicato de Obreros y Empleados del Azúcar del Ingenio Ledesma (SOEAIL), seguida por la conformación del Sindicato de Obreros y Empleados de Calilegua, poco tiempo más tarde. En el marco del proceso de organización sindical, los trabajadores/as de Ledesma participaron de diversos procesos importantes; por ejemplo, en mayo de 1963 participaron del plan de lucha iniciado por la Confederación General del Trabajo, una movilización contra el hambre, la desocupación, en defensa de los jubilados y por la libertad de los presos del Plan Conmoción Interna del Estado (CONINTES). En Jujuy, en esa oportunidad se suspendió la molienda de la caña de azúcar y dos años más tarde se realizaron paros a lo largo de varios meses.

A comienzos de 1964, la Gendarmería de la zona de Orán, en Salta, había desarticulado el Ejército Guerrillero del Pueblo, una experiencia guerrillera foquista dirigida por Jorge Ricardo Masetti y apoyada desde Cuba por Ernesto "Che" Guevara. Una fuerte hipótesis militar consistía en considerar la zona como un canal de infiltración del "comunismo internacional". En este marco, en abril de 1966 el decreto presidencial 2379 creó una subunidad de Gendarmería en Ledesma "para controlar los pasos fronterizos y los movimientos migratorios, entre los meses de marzo a diciembre de todos los ingenios de Salta y Jujuy"; no obstante, esta no se instaló en la frontera sino en la localidad donde la compañía desarrollaba sus negocios. Ledesma SAAI cedió espacio en su propiedad para la instalación del puesto de Gendarmería y para la vivienda de los oficiales y soldados. La colaboración con esta fuerza se amplió también al abastecimiento de combustible y el mantenimiento de los vehículos. ${ }^{21}$

Hacia 1967, el sindicato de Calilegua pasó a estar bajo una dirección encabezada, entre otros, por Agustín Donato Garnica, quien llevaba allí décadas como trabajador. En 1969 comenzaron los despidos masivos en Ledesma, y en los años siguientes los trabajadores del azúcar de Salta y Jujuy se plegaron con paros propios a las movilizaciones de los trabajadores de Altos Hornos Zapla, Mina Aguilar y los docentes y empleados públicos de dichas provincias. En 1971 se produjo el levantamiento popular conocido como “Jujeñazo", que tuvo su epicentro en la capital provincial.

particular en el que, al contrario de lo que sucede en la industria capitalista 'típica', la empresa invade y domina no solo la esfera de la producción sino también la esfera de la reproducción de los trabajadores”. Ver Gómez y Karasik, De la acción social transformadora, 11.

21 AEyT de FLACSO y otros, Responsabilidad empresarial. 
En esa época, en el ingenio Ledesma, el sindicato era considerado uno de los medios utilizados por la empresa para controlar y disciplinar las demandas laborales. Cuando la apertura de la fábrica de papel del Ingenio Ledesma permitió plantear a los trabajadores de la nueva planta la discusión por el encuadramiento gremial, surgió la iniciativa de conformar un sindicato local de trabajadores de la fábrica de papel de Ledesma. Sin embargo, la respuesta empresarial fue el despido y la persecución. Los trabajadores denunciaron el despido de todos los integrantes de la comisión directiva de la nueva organización y comentaban asimismo que "en el pueblo de Libertador General San Martin 'Ledesma' de la Provincia de Jujuy aún se vive bajo un régimen semifeudal (...) cuando un trabajador deja de pertenecer a la empresa, indefectiblemente debe dejar de pertenecer a esa población también". ${ }^{22}$

Bajo esas circunstancias un grupo de trabajadores azucareros comenzó a organizarse clandestinamente con la idea de recuperar el sindicato. Tomaron la denominación de Grupo de Obreros de Ledesma (GOL), siendo Jorge Weisz, técnico en la empresa y militante de Vanguardia Comunista, uno de los integrantes que tuvo un rol clave en el proceso de organización. ${ }^{23}$ A pesar del miedo y las persecuciones, el prestigio del GOL fue creciendo y hacia 1972 lograron que fueran electos delegados varios de sus integrantes: Jorge Weisz, Carlos Figueroa, Melitón Vázquez, Crecencio Vargas y Hugo Condorí. Aquel año, una asamblea decidió que Vázquez viajara a Buenos Aires para participar de las paritarias sectoriales, lo que además sirvió para fortalecer las relaciones con los dirigentes de la federación de trabajadores azucareros de Tucumán. ${ }^{24}$

En 1973 se conformó una lista opositora en cuyo frente se postuló a Vázquez. A partir del triunfo de la lista, el sindicato se convirtió en una de las principales fuentes de oposición al dominio que ejercía la empresa tanto en la fábrica como en los distintos órdenes de la vida, librándose a partir de ese momento grandes batallas por el cumplimiento de los derechos de los trabajadores. A ello se agregó que no solo los trabajadores de la fábrica consiguieron organizarse, sino que pronto se sumaron activamente sus pares del surco. Por otro lado, abogados laboralistas como Carlos Ernesto Patrignani solidificaban el trabajo gremial de base demandando aumentos salariales, mejoras en las condiciones de trabajo para los zafreros y la efectivización de los trabajadores temporarios, entre otras cuestiones.

Con el cambio de dirección sindical comenzaron a hacerse frecuentes las medidas de fuerza, no solo en las secciones de la fábrica, sino también en el

22 AGN-AI, Exp. No 485.686/71, p. 212.

23 Delia Maisel, Memorias del Apagón. La represión en Jujuy: 1974-1983 (Buenos

Aires: Ediciones MEDH, 2006), 69.

24 Nelli, La injusticia cojuda. 
campo, en el sector zafrero. Se realizaron también paros de bolseros, cortes de caminos y movilizaciones, así como medidas en la central termoeléctrica por falta de pago. A pesar de encontrarse vigente el Pacto Social a nivel nacional, que buscaba contener los conflictos sindicales, la huelga más importante que duró varios días contó con la solidaridad activa de líderes sindicales de importancia nacional como René Salamanca y Raimundo Ongaro, quienes visitaron Libertador San Martín. Entre otras demandas, los trabajadores reclamaban una sala de atención médica con médico permanente, odontólogo, viviendas dignas, agua potable y electricidad. En paralelo, el sindicato terminó por romper las fronteras empresariales que cerraban el territorio con la intervención de la Subsecretaría de Salud Pública del gobierno provincial en Ledesma, que envió una comisión de inspección que relevó las pésimas condiciones a las que eran sometidos los trabajadores. La empresa fue multada luego de vencido el plazo para adecuar los servicios del trabajo. 25

$\mathrm{Al}$ tiempo que se reclamaban urgentes mejoras y el cumplimiento de las leyes provinciales que obligaban a la empresa con relación a la asistencia médica de los trabajadores y a la provisión de viviendas dignas, en junio de 1973 Luis Ramón Aredez se convirtió en el nuevo intendente del municipio Libertador General San Martín. Aredez era médico y había trabajado para Ledesma hasta agosto de 1958, cuando fue despedido. ${ }^{26} \mathrm{Al}$ poco tiempo, consiguió una casa e instaló su consultorio en el pueblo para atender a los trabajadores y comenzó a asesorar al sindicato en materia de salud, siendo acompañado por otro exmédico de la empresa, Carlos Alberto Cardozo, también despedido por haber denunciado la deficiente atención médica que ofrecía la compañía.

En el poco tiempo que Aredez fue intendente se realizaron importantes cambios en el municipio, como la ampliación del ejido municipal para demarcar los límites de la ciudad, incluyendo dentro del distrito al complejo fabril de Ledesma y reasignando terrenos de la compañía para efectuar la nueva urbanización. ${ }^{27}$ La nueva gestión proyectó además la construcción de viviendas para más de tres mil personas, se realizaron obras de pavimentación de rutas, enripiado y ensanchamientos de calles y construcción de cordones y cunetas, se extendió la red de gas natural, se refaccionaron baños públicos, el cementerio, el edificio administrativo, el mercado y el matadero municipal,

25 AEyT de FLACSO y otros, Responsabilidad empresarial.

26 Victoria Basualdo, "Complicidad patronal-militar en la última dictadura argentina: Los casos de Acindar, Astarsa, Dálmine Siderca, Ford, Ledesma y Mercedes Benz”, en suplemento especial de la revista Engranajes de la Federación de Trabajadores de la Industria y Afines, marzo 2006. También disponible en:

https://www.comisionporlamemoria.org/archivos/jovenesymemoria/bibliogra fia_web/ejes/transformaciones_basualdo.pdf

27 Basualdo, "Complicidad patronal-militar". 
y las instalaciones eléctricas urbanas; se hicieron trabajos de mejoras en la potabilización del agua, entre otras. En este marco se confeccionó además una nueva ordenanza y el código tributario, y se exigió la tributación de la empresa Ledesma, lo que implicó un punto de inflexión muy significativo en la relación del gobierno local con la empresa. En paralelo, desde la gobernación provincial se anunciaba el envío a la Legislatura de un proyecto de expropiación de tierras en la zona para que fueran entregadas a los trabajadores y la pronta reglamentación de la ley provincial de vivienda obrera.

Muchos de estos cambios que se fueron produciendo a partir de 1973 estuvieron acompañados por despidos selectivos de los obreros militantes más activos. A comienzos de 1974, el sindicato de Ledesma denunció el despido de más empleados y obreros con la excusa de una supuesta reorganización administrativa, mientras comenzaban a correr rumores de que se estaba gestando una intervención del SOEAIL y Ledesma prohibía el ingreso del asesor legal del sindicato a las reuniones con los directivos impidiendo a los trabajadores el derecho democrático de ser asistidos legalmente. En paralelo, se intensificó la presión sobre el intendente, llegándose a una situación en la que Aredez debió renunciar, en febrero de 1974. Sin embargo, el sindicato se movilizó para apoyar la gestión municipal y revertir la decisión del intendente.

Este fue el contexto en que se produjo una persecución y represión que tuvo como centro no solo a los trabajadores/as, sino también a sus familias y allegados, a los abogados asesores del sindicato y defensores de los trabajadores, y a las figuras políticas de la zona que habían desafiado el poder empresarial. ${ }^{28}$ Las primeras detenciones se produjeron en agosto de $1974 \mathrm{y}$ desde esa fecha hasta julio de 1976 la represión continuó con aún mayor intensidad en etapas sucesivas: en marzo y abril de 1975, con la intervención del sindicato e inmediata represión; en marzo de 1976; y, finalmente en julio de 1976, cuando se produjo la conocida "Noche del apagón”, nombre con el que se conoce a una serie de operativos represivos de secuestros que se produjeron en las noches sucesivas del 19 al 22 de julio de 1976, en el marco de un corte de energía eléctrica en toda la zona. Solo existe registro de un secuestro y desaparición posterior a estas fechas, en 1979.

Como lo muestra el informe de Responsabilidad Empresarial en 2015, en el marco de estos ciclos represivos cientos de personas resultaron víctimas del terrorismo de Estado en las localidades de Libertador General San Martín y

28 Los abogados laboralistas Carlos Alberto Patrignani y José Pablo Bernard fueron víctimas del terrorismo de estado por su acción en defensa de los derechos de los trabajadores. 
Calilegua. ${ }^{29}$ De al menos unas sesenta personas se sabe que eran empleados u obreros de la empresa -operarios de fábrica o zafreros-, o que tenían un rol activo en los sindicatos de trabajadores de Ledesma o de Calilegua. Sin embargo, también docentes, médicos, abogados y estudiantes de dichas localidades, vinculados a la compañía, fueron víctimas de la represión debido al extendido dominio que el Ingenio Ledesma había consolidado en la zona a lo largo de varias décadas. Del total de víctimas, casi una treintena fue desaparecida, otras tantas estuvieron en condición de desaparecidas en centros clandestinos de detención pero sobrevivieron, mientras que más de veinte sufrieron la detención y luego fueron liberadas, no teniéndose datos precisos para otro grupo de víctimas.

La investigación realizada en el marco del proyecto de Responsabilidad Empresarial en delitos de lesa humanidad, así como la prueba analizada y valorada en el ámbito judicial, permitieron probar que la compañía no solo colaboró activamente, sino que participó en la planificación de dichos delitos. Numerosos testimonios y documentos enseñan cómo directivos y altos empleados del ingenio Ledesma se involucraron en los secuestros de los trabajadores, algunos de los cuales se produjeron en la misma fábrica. Asimismo, diversas fuentes confirman el uso de camionetas de la empresa para el desarrollo de los secuestros, así como la entrega de listas de personas a detener que fueron provistas por funcionarios de la compañía. La participación de la empresa en una comunidad informativa ilegal, de carácter persecutorio, los estrechos vínculos de los directivos, incluido el dueño Carlos Pedro Blaquier, con los agentes de la represión, el rol clave de exmilitares como funcionarios privados, entre otros elementos, iluminan la responsabilidad empresarial en los crímenes de lesa humanidad.

\section{El Proceso de Memoria, Verdad y Justicia de Ledesma}

El caso de Ledesma fue visibilizado y denunciado desde la Conadep, en 1984, y el juicio a las Juntas, en el marco del cual se escucharon testimonios conmovedores, como el de "Rita" Eublogia de Garnica, que denunciaron fuertemente el proceso represivo y el papel de la empresa. Olga Arédez, la esposa del desaparecido exintendente Luis Arédez, se convirtió en una figura

29 Resulta muy difícil cuantificar la cantidad de víctimas, en particular debido a la masividad de los operativos represivos que se llevaron adelante, como ejemplo puede citarse que las pruebas de las causas disponibles señalan la existencia de más de doscientos detenidos en los operativos de julio de 1976. Se toman aquí los datos del informe realizado por AEyT de FLACSO y otros, en el que se reconstruye un listado que se basa en los casos judicializados y los que pudieron identificarse por fuera del marco judicial, aclarando que no se tiene certeza de que abarque la totalidad de las víctimas. 
emblemática de la denuncia a las violaciones a los derechos humanos a partir de un sostenimiento de la lucha aún en contextos de soledad y persecución. En el período 2003-2015, en un contexto de ampliación y profundización de las políticas de derechos humanos, se generaron nuevos movimientos sociales y políticos en Jujuy, muchos de los cuales tomaron el caso de Ledesma y en particular "La Noche del Apagón", realizando por primera vez movilizaciones multitudinarias con participación de organizaciones y militantes de todo el país. Este proceso de movilización y denuncia tuvo mucha incidencia en la persecución desatada desde diciembre de 2015, bajo el gobierno de Mauricio Macri, contra figuras políticas de la provincia como Milagro Sala, líder de la organización Túpac Amaru, quien fue perseguida y encarcelada, y se encuentra cumpliendo prisión domiciliaria hasta la actualidad. ${ }^{30}$

En términos del proceso de judicialización en el ámbito penal, Carlos Pedro Blaquier, dueño del ingenio Ledesma, y Alberto Lemos, administrador general de la empresa en la etapa en que se cometieron las violaciones a los derechos humanos, fueron procesados en noviembre de 2012 por privación ilegal de la libertad en dos causas, por los secuestros de 29 trabajadores y referentes sociales ocurridos entre marzo y julio de 1976. El juez de instrucción, Fernando Poviña, señaló como uno de los elementos centrales la cesión de camionetas del ingenio para el secuestro y traslado de prisioneros; que dicha sesión no estaba registrada, que fueron entregas ocultas, sin control y que, justamente, no eran "inocuas", sino que se hacían en un contexto histórico determinado: una época de fuerte persecución política y sindical a trabajadores o líderes sindicales. Explicó que la empresa tenía antecedentes de disputa con esos mismos sindicalistas, y que existieron sanciones o llamadas de atención de parte de la empresa a esos trabajadores, e incluso actividad de inteligencia realizada sobre ellos para ver qué tarea sindical realizaban, y en muchos casos despidos. Los datos estuvieron apoyados por una abundante profusión de documentos: el acuerdo entre Blaquier y el represor Antonio Domingo Bussi; la instalación de un puesto de Gendarmería Nacional en un predio ubicado en las inmediaciones del ingenio, una fuerza de frontera que quedó ubicada así a varios kilómetros de la frontera real con Bolivia y estaba allí para "cubrir el avance del comunismo". Se agregaron documentos sobre la intervención de Blaquier en el grupo Azcuénaga, un agrupamiento de sectores empresariales y políticos que fue clave en la preparación del golpe de Estado, y la solicitada de apoyo a la dictadura publicada por Ledesma un año después del golpe. El procesamiento fue confirmado en 2013 por la Cámara Federal de Apelaciones de Salta.

30 Alejandra Dandan y Hannah Franzki, "Entre análisis histórico y responsabilidad jurídica: El caso Ledesma”, en Verbitsky y Bohoslavsky, Cuentas pendientes. 
Ante la apelación de las defensas, la Sala IV de Casación, integrada por Gustavo Hornos, Juan Carlos Gemignani y Eduardo Riggi, tomó el expediente en diciembre de 2013. Los jueces se pronunciaron en marzo de 2015, dictando la falta de mérito en beneficio de Blaquier y Lemos. Al mismo tiempo que consideraron probado que la empresa aportó vehículos para los secuestros, negaron en el fallo que pudiera considerarse probado que el dueño y administrador del ingenio hubieran conocido los fines para los que se usaron estas camionetas. De acuerdo con fuentes especializadas, son muy pocos los precedentes en que la Cámara de Casación se atrevió a analizar los elementos fundamentales para un procesamiento y a intervenir en cuestiones "de fondo" en un caso en que no se hubiera alcanzado una sentencia, por lo que esta intervención fue considerada como una excepción. ${ }^{31}$ Aún más significativo es el hecho de que la apelación de dicha decisión ante la Corte Suprema de Justicia de la Nación, realizada ese año, aún sigue pendiente de respuesta en 2021, a seis años de su presentación, a pesar del reclamo sostenido de las víctimas y de amplios sectores sociales.

Debido a esto, cuando el 21 de junio de 2018 se inició en el Tribunal Oral Federal N. ${ }^{\circ} 1$ de Jujuy la etapa oral de una megacausa que acumuló 16 causas, incluyó 113 víctimas, 38 detenidos-desaparecidos y 75 sobrevivientes, y tiene 23 imputados pertenecientes a distintas fuerzas de seguridad que operaron en distintos Centros Clandestinos de Detención, un dato de extrema relevancia fue la exclusión de los responsables empresariales del listado de los imputados. Esta causa histórica permitió sin embargo escuchar las voces de las víctimas que aún sobreviven, y una gran cantidad de testigos que se refirieron a las numerosas violaciones a los derechos humanos que incluyen, entre otras, violación de domicilio, privación ilegítima de la libertad agravada, torturas, homicidio calificado, violación sexual agravada, allanamiento ilegal, severidades, apremios ilegales, así como violencia de género y sexual, que se planteó en forma diferenciada con el objetivo de que pueda ser condenada como tal. Sin embargo, a pesar de que esta causa incluye casos de trabajadores/as y sindicalistas del Ingenio Ledesma -también de otras empresas con evidencias de responsabilidad empresarial en delitos de lesa humanidad, como la Mina "El Aguilar"-y por lo tanto involucra aspectos referidos a la responsabilidad civil-empresarial durante la dictadura, no hay imputados empresariales incluidos en la misma.

31 Victoria Basualdo, "Empresas, crímenes de lesa humanidad y justicia transicional en Argentina”, en dossier "Empresas y Derechos Humanos. Avances, desafíos y propuestas para una agenda colaborativa”, Revista electrónica del Consejo de Derechos Humanos de la Defensoría del Pueblo de la Ciudad de Buenos Aires, 2020. 


\section{El caso de la empresa yerbatera y de producción de té "Las Marías", provincia de Corrientes}

En la región noreste de la República Argentina, que abarca las provincias de Misiones, Corrientes, Entre Ríos, Chaco y Formosa, la producción primaria y agroindustrial tiene un peso fundamental en la estructura económica. Una de las actividades más antiguas y relevantes en Corrientes y Misiones es la producción de yerba mate -inicialmente propia de los pueblos originarios y luego asimilada por los conquistadores- que fue posible mediante la explotación violenta de fuerza de trabajo nativa. ${ }^{32} \mathrm{Al}$ visitar campamentos yerbateros en 1894, el etnógrafo J. B. Ambrosetti imprimía sus impresiones, especialmente de los tareferos, ${ }^{33}$ de este modo: "cantidad de gente de colores, raza y nacionalidad distintas, con el pelo y la barba largos, flacos, demacrados, con la ropa hecha jirones, casi desnudos, viviendo en miserables ramadas con sus mujeres e hijos". Otras fuentes indican salarios reducidos, alimentación escasa, abrumadoras jornadas, proveedurías deshonestas, entre otras estrategias patronales. ${ }^{34}$ Durante las primeras décadas del siglo XX se produjeron las primeras huelgas en demanda de mejores condiciones de trabajo y de negociación con los grandes compradores y comerciantes, pero fueron reprimidas bajo acusación de "anarquismo" y "comunismo", y las condiciones de trabajo continuaron siendo deplorables. ${ }^{35}$

Un hito posterior muy importante fue la promulgación del Estatuto del Peón rural en 1944, bajo la actuación del coronel Perón en la Secretaría de Trabajo y Previsión. Si bien durante el período peronista surgieron importantes organizaciones obreras, posteriormente en el marco del derrocamiento del peronismo y el inicio de una serie de dictaduras, investigaciones de la época

32 Javier Gortari, "Maldita yerba mate: explotación de la mano de obra en las "minas yerbateras" del Paraguay colonial” (cap.1) y "Acumulación originaria: trabajo esclavo y connivencia de gobierno” (cap.2), en Daniel Re, María Luz Roca y Javier Gortari, Tareferos. Vida y trabajo en los yerbales (Posadas: Editorial Universitaria de Misiones, 2017), 31-90.

33 Los tareferos son quienes cortan la yerba. En Misiones se los conoce como los "mensú" modernos, sometidos a ciclos de endeudamiento que se renuevan año a año: "La metodología adoptada en este caso es una variante del 'peonaje por deudas' con retención forzosa de la mano de obra en los lugares de trabajo. Se utilizan modalidades de "enganchamiento" para apropiarse de la capacidad laboral de una población nativa”. Víctor Rau, "Transformaciones en el mercado de fuerza de trabajo y nuevas condiciones para la protesta de los asalariados agrícolas”, en Norma Giarracca y Bettina Levy (eds.), Ruralidades Latinoamericanas. Identidades y luchas sociales (Buenos Aires: CLACSO, 2004), 441.

34 Ver Niklison, 1914, citado en Gortari, “Acumulación originaria”, 62.

35 Delia Ramírez, "Tradición movimientista. Una categoría para pensar las relaciones de continuidad y ruptura entre organizaciones agrarias históricas y contemporáneas de Misiones”, Mundo Agrario, 15, 28, (2014). 
dieron cuenta de que las condiciones de trabajo continuaban siendo deplorables en las colonias yerbateras. ${ }^{36}$

La empresa "Las Marías" analizada aquí, propiedad de la familia Navajas Artaza, resulta fundamental en esa producción. Está ubicada en la localidad de Gobernador Virasoro en el nordeste de la provincia de Corrientes aunque también cuenta con estancias y tierras en la provincia de Misiones. Expandió sus actividades productivas al cultivo de té y actividades ganaderas y forestales manteniendo, sin embargo, un lugar privilegiado dentro del mercado yerbatero argentino. ${ }^{37}$ La localidad de Virasoro creció al ritmo de la expansión de una empresa que, como propietaria de muchas de las tierras loteadas en la fundación de la localidad, promovió la conformación de una gran cantidad de estancias y establecimientos satélites; por ello, gran parte de los pobladores se encuentran relacionados laboralmente de manera directa $\mathrm{o}$ indirecta.

El poder económico y el poder político se encuentran fuertemente emparentados: de hecho, el principal referente de la empresa, Adolfo Navajas Artaza, ocupó importantes cargos políticos a partir de la autodenominada "Revolución Libertadora" que derrocó a Perón y de la cual se reconoce como artífice. Asimismo, se tejieron relaciones de dependencia por la gran presencia comunitaria de estas familias en instituciones sociales fundamentales como clubes y establecimientos deportivos, instituciones educativas, servicios médicos, barrios de vivienda, entre otros, lo que permitió y aún permite mecanismos de control social muy marcados.

En la década de 1970, en un contexto político nacional de gran movilización social que dio lugar al surgimiento de dirigencias sindicales combativas, de las ligas agrarias vinculadas al Movimiento Rural de Acción Católica y del movimiento de curas tercermundistas, los trabajadores industriales y rurales de la empresa lograron organizarse gremialmente. Se agruparon en dos organizaciones: el Sindicato de Trabajadores de la Industria de la Alimentación (STIA), que representaba a los trabajadores de la industria dedicados a las últimas etapas del proceso productivo, y la Federación Argentina de Trabajadores Rurales y Estibadores (FATRE), que representaba a los trabajadores del campo, de los montes. Estos últimos sufrían las peores condiciones de trabajo, al igual que los trabajadores del sector "industrial" que también estaban expuestos a maltratos, explotación, malas condiciones de salubridad e higiene, accidentes y violación de derechos

36 Investigación a cargo del Grupo de trabajo en Sociología Rural del Ministerio de Agricultura y Ganadería de la Nación, citado en Gortari.

37 Pablo J. Schamber, "Éxito y ocaso de un estilo de gestión empresarial. El caso del Establecimiento Las Marías en el sector yerbatero”, en Realidad Económica, 181 (2001): 131-150. 
laborales. Muchos de los trabajadores, además, vivían en viviendas y/o pabellones de propiedad de la empresa y estaban sometidos a un sistema de vigilancia y control estricto, que remite a los "sistemas de fábrica con villa operaria”, como una de las formas de inmovilización forzada de la fuerza de trabajo. $^{38}$

Esta coyuntura de movilización política y sindical no fue ajena a la empresa Las Marías, que en 1974 enfrentó una huelga de 48 horas con repercusión nacional. Esa medida se inició a raíz de que una mujer embarazada, sublevándose contra el autoritarismo empresarial que le negaba ir al baño y concurrir al médico, se retiró del trabajo y por ello fue despedida, lo que inició la huelga. El conflicto logró nuclear al STIA y a la FATRE y fue histórico no solo por tratarse de la primera medida de lucha de esa envergadura sino porque tuvo lugar en el marco de un acto conmemorativo de aniversario por la muerte de Víctor Navajas Artaza, fundador de la empresa, algo que, desde la perspectiva obrera, fue imperdonable para los patrones.

Todo el proceso de organización obrera fue interrumpido abruptamente por la dictadura militar. El 24 de marzo de 1976 el municipio fue intervenido militarmente. El administrador de una de las estancias vinculadas a la empresa, la estancia “María Aleida", teniente $1^{\circ}$ retirado Héctor María Torres Queirel, fue designado interventor municipal y la Comisaría Departamental fue puesta a cargo del Capitán Juan Carlos Sacco, ${ }^{39}$ quien dirigió los operativos represivos desde los primeros días del golpe.

En abril de 1976 fueron secuestrados los secretarios generales de los sindicatos que actuaban en Las Marías, Marcelo Acuña y Ramón Aguirre, y el tesorero del STIA, Pablo Franco. En agosto fueron detenidos otros dos empleados, Hipólito Mendieta y Pedro Celestino, a raíz de una denuncia impulsada por un empleado jerárquico de la empresa. Luego, entre febrero y julio de 1977, fueron secuestrados otros ocho trabajadores con distintos niveles de participación gremial: Juan Manuel Gómez, Héctor Sena, Epifanio Monzón, Carlos Arturo Escobar Solano, Ramón Peralta, Jacinto Bernal, Neris Pérez y Marcelo Peralta. Los dos últimos permanecen desaparecidos.

Luego de las detenciones de 1977, se formalizaron causas judiciales contra los trabajadores detenidos acusados de infringir la Ley $20.840,4^{40}$ a partir de

38 José Sergio Leite Lopes, Mudança social no Nordeste. A reprodução da subordinação (Rio de Janeiro: Paz e Terra, 1979); Federico B. Neiburg, Fábrica y villa obrera: historia social y antropología de los obreros del cemento (Buenos Aires: CEAL, 1988).

39 Libro Histórico del Escuadrón de Exploraciones Caballería Blindado 7 de Santo Tomé, 1976, p. 3.

40 Ver inciso 6 de la Ley 20.840/74: "Penalidades para las actividades subversivas en todas sus manifestaciones". A raíz de la supuesta infracción, se abrió el expediente $\mathrm{N}^{\circ} 1-1.586 / 77$. 
supuestos actos de sabotaje industrial en el marco de actividades subversivas. Además, se los señalaba como militantes del PRT-ERP, organización político militar acusada de realizar acciones de "chequeo" de Adolfo Navajas Artaza. Según pudieron testimoniar posteriormente los detenidos, en aquellos años se les tomó declaración indagatoria bajo presión, provocando su autoincriminación o el señalamiento de los otros acusados.

La participación de la empresa en la represión a sus trabajadores fue evidenciada en la investigación anteriormente mencionada. ${ }^{41}$ A partir de la revisión de archivos y testimonios se demostraron una serie de prácticas empresariales represivas. Funcionarios de la empresa realizaron una serie de denuncias, acusaciones y señalamientos que tuvieron como consecuencia la persecución y en algunos casos el secuestro de trabajadores: denuncias sobre sabotajes, la acusación de "puente subversivo" por parte de importantes directivos contra trabajadores, la denuncia por parte de un empresario local por malversación de caudales públicos y cohechos; y finalmente, la denuncia de defraudación por parte de un empleado jerárquico de Las Marías. Si bien posteriormente se demostraron infundadas, fueron una manera operativa de lograr la represión de los trabajadores sindicalizados de la empresa.

Otra serie de prácticas represivas empresariales se relacionan con los aportes logísticos y materiales para llevar a cabo la represión. Uno de los trabajadores afirmó que lo secuestraron en un vehículo aportado por la empresa a las fuerzas militares en agosto de 1976. Otros testimonios indican la presencia del Ejército para la realización de reuniones en el establecimiento y la utilización de sus instalaciones, así como la utilización de la pista de aterrizaje de la firma. Por otro lado, existen pruebas que indican que la empresa habría cedido sus territorios o establecimientos estrechamente vinculados para la instalación de campamentos militares, utilizados en el marco del operativo militar llamado "Consolidación" en 1977. ${ }^{42}$

Asimismo, la empresa permitió el secuestro de trabajadores dentro de predios de su propiedad y/o de campos vinculados directamente a las actividades productivas de la empresa. Uno de los casos sobresalientes, a partir de los cuales fue imputado Torres Queirel, fue el secuestro de Marcelo Peralta, quien vivía con su pareja y una bebé en una precaria vivienda dentro de la

41 AEyT de FLACSO y otros, Responsabilidad empresarial. Ver también Andrea Copani, "Las Marías y la dictadura: responsabilidad empresarial en la represión a trabajadores durante el terrorismo de Estado en una empresa del noreste argentino", en La Rivada. Revista de investigaciones en ciencias sociales, 5 (2017): 46-58.

42 Durante el proceso judicial desarrollado en 2018, en su alegato, la Fiscalía aportó pruebas respecto de que hasta 15 días antes del secuestro de Peralta, la estancia de Torres Queirel había sido utilizada para la instalación de un vivac (base militar operativa), en el marco del Operativo "Consolidación”. 
estancia "María Aleida", propiedad de Torres Queirel, que no solo era el interventor militar del municipio sino que estaba vinculado a Las Marías. En un operativo nocturno de envergadura, fue secuestrado Marcelo y amenazada su compañera.

La presencia militar y policial en la planta fue clave a partir del golpe. Agentes de la policía también cumplían funciones en Las Marías, como es el caso del policía José Anchetti, quien posiblemente realizaba tareas de inteligencia y luego participó en los secuestros de trabajadores. Por otro lado, testimonios indican que la empresa tomó decisiones de gestión de la fuerza de trabajo y aportó información que facilitó la realización de los secuestros de trabajadores. Es el caso de Neris Pérez, quien fue detenido un día en que se le había concedido un franco extraordinario. Otro trabajador fue secuestrado en la pieza que ocupaba en el pabellón de solteros dentro de Las Marías, también en un día de descanso extraordinario concedido por la empresa.

La represión tuvo como objetivo a trabajadores sindicalizados $\mathrm{y} / \mathrm{o}$ reconocidos activistas gremiales. Sobrevivientes testimoniaron que se los interrogaba, bajo tortura, por su participación sindical. Asimismo, fueron detenidos dos abogados laboralistas relacionados con los sindicatos actuantes en la empresa. ${ }^{43}$

Finalmente, existían vínculos personales y políticos entre los dueños de la empresa y las Fuerzas Armadas. El caso del mencionado Torres Queirel y el propio Adolfo Navajas Artaza, que se desempeñó como ministro de Acción Social durante la presidencia de facto del general Reynaldo Bignone.

Todos estos elementos permitieron afirmar que la empresa tuvo responsabilidad en la comisión de delitos de lesa humanidad contra los trabajadores, ya sea con aportes logísticos, materiales, de infraestructura, información y facilitación operativa para los secuestros; por las características que asumieron los interrogatorios, por las vinculaciones fuertes entre los empresarios, fuerzas militares y poder político. Se desprende de este análisis que el objetivo principal de la represión fue la destrucción de la organización gremial, siendo víctimas especialmente sus principales referentes.

\section{El proceso de judicialización en un contexto de continuidad del dominio político económico y territorial}

En este apartado tenemos el objetivo de realizar algunas brevísimas reflexiones sobre el proceso judicial y cómo estos hechos tienen la capacidad

43 Los abogados eran Julio Rito Gervasoni y Moisés Belsky (ver AEyT de FLACSO y otros, Responsabilidad empresarial, tomo 2, 296-297). 
de expresar la sobrevivencia de relaciones de dominio político, económico y territorial por parte de la empresa. ${ }^{44}$

La sentencia dictada por el Tribunal Oral Federal de Corrientes, el 23 de agosto de 2018, absolvió al único imputado: el ex interventor municipal y empresario yerbatero Héctor María Torres Queirel. A Torres Queirel se lo investigaba por su responsabilidad en la represión de la región y además porque era dueño y residente de la estancia María Aleida, desde donde fue secuestrado y posteriormente desaparecido un trabajador. A pesar de las pruebas ofrecidas por la Fiscalía y en un marco de serias irregularidades que fueron expuestas en los alegatos, el imputado fue absuelto. ${ }^{45}$

La causa conocida como "Las Marías" ha tenido un derrotero que incluye dilaciones e irregularidades que derivaron en un achicamiento de la causa a tal punto que finalmente no pudieron ser juzgados varios de los imputados iniciales, ${ }^{46}$ entre ellos, Adolfo Navajas Artaza, ${ }^{47}$ el principal referente empresarial. Por otro lado, muchas de las víctimas iniciales tampoco pudieron acceder al proceso de justicia. ${ }^{48}$

44 Este apartado está sustentado en la participación de una de las autoras del artículo en viajes de acompañamiento al juicio, en conversaciones y reuniones con familiares, víctimas y funcionarios judiciales. Algunas reflexiones iniciales fueron publicadas en un artículo previo. Ver Andrea Copani y María Alejandra Esponda, "Prácticas empresariales represivas durante la última dictadura cívicomilitar. El caso del Establecimiento Las Marías", en Revista Trabajo y Derechos Humanos 5, 3 (2018).

45 Entre ellos, el fiscal presentó un pedido de explicación al Tribunal al enterarse que, luego de haber suspendido una visita ocular a la estancia donde secuestraron a Peralta, el Tribunal se había movilizado a la estancia sin dar aviso a las partes, lo que constituyó una irregularidad que hubiera sido suficiente para recusar al Tribunal.

46 En el contexto de reapertura de los procesos judiciales por delitos de lesa humanidad, el colectivo de familiares de desaparecidos y ex detenidos de Gobernador Virasoro, militantes de derechos humanos lograron que se diera inicio a una causa judicial en 2006. En el año 2010, fue unificada con otra causa en la que se investigaba delitos cometidos contra otros trabajadores del establecimiento, quedando imputados solamente efectivos militares. En abril de 2014, el expediente judicial fue elevado a juicio oral pero fue pospuesto por el Tribunal Oral Federal de Corrientes, con el argumento de la precaria condición de salud de los acusados. En ese lapso fallecieron trabajadores testigos fundamentales para la causa, como así también los responsables de los delitos, oficiales Duilio Martínez y Ricardo Schweizer, y otros como el coronel Llamil Reston y el capitán Juan Carlos Sacco fueron apartados por razones de salud.

47 A quien se lo sobreseyó en 2008 sin siquiera habérsele tomado declaración indagatoria.

48 Una muestra de las irregularidades y la importancia del poder empresarial actual fue la excusación de una veintena de jueces por sus relaciones con los propietarios de la empresa yerbatera. Para una revisión más exhaustiva del 
El colectivo de familiares, víctimas y militantes de derechos humanos conocían las grandes dificultades que enfrentaban para que se hiciera justicia. Sin embargo, para ellos y ellas el juicio tenía objetivos que trascendían el resultado final. Uno de los objetivos era visibilizar, en la localidad, lo que había ocurrido allí durante la dictadura militar. Hacer público el juicio y los apoyos recibidos desde distintos lugares del país fue el motor de una marcha realizada el domingo previo al comienzo del juicio. Este hecho, para muchos, fue histórico y reparatorio. Recorriendo las calles y cantando consignas que denunciaban los crímenes, responsabilizaban a la empresa y recordaban a los trabajadores desaparecidos. Cuando un asistente gritaba sus nombres los marchantes respondían: “¡Presente!”, "Presente”, “Ahora y siempre”. De esa manera se lograba develar aquel "secreto público" que llevaba décadas sin salir a la luz. ${ }^{49}$

Sin embargo, ni bien comenzó el debate oral, el peso de las instituciones y el dominio económico, político y territorial se hicieron sentir y convirtieron el escenario judicial en un espacio de tensión, temor e indignación. En gran medida, fue el propio tribunal ${ }^{50}$ el que tomó decisiones contrarias a que el juicio fuera un acto reparatorio: militarización del espacio con gendarmes y policías en las cercanías y dentro del recinto, y controles indignos sobre las personas asistentes ${ }^{51}$ fueron permanentes los días en que se desarrolló el juicio. Los extrabajadores y sus familiares, esposas, hijas e hijos dieron su testimonio frente a un tribunal cuyo presidente, luego de saludar y reverenciar a fuerzas militares y policiales presentes e incluso a familiares del imputado, marcaba una actitud de suma hostilidad y rechazo frente a ellos. Luego de décadas de silencio y temor, iban a contar qué les había ocurrido y cómo habían vivido aquellos años, y en muchos casos eran interrumpidos por un juez que les informaba que sus dichos se alejaban del "objeto procesal”, les

derrotero de la causa judicial ver: https://www.elcohetealaluna.com/matelavado/ y de las distintas instancias durante el desarrollo del juicio en primera instancia ver entre otras las siguientes notas periodísticas:

https://www.letrap.com.ar/nota/2018-7-4-10-48-0-el-historico-juicio-por-lasmarias-en-un-escenario-de-fuerte-militarizacion;

https://www.pagina 12.com.ar/138263-esto-traza-una-linea-de-impunidad; https://www.pagina12.com.ar/126053-la-verdad-y-la-justicia-llegaron-acorrientes

49 Byung-Chul Han, Topología de la violencia (Barcelona: Herder Editorial, 2016).

50 Tribunal compuesto por Víctor Alonso, Lucrecia Rojas de Badaró y Fermín Ceroleni.

51 En primer lugar, gendarmes requisaban a cada asistente en un cuarto cerrado. En dos oportunidades se obligó a los asistentes a utilizar los sanitarios en presencia de gendarmes. Finalmente, una de las asistentes fue obligada a desvestirse completamente antes de ingresar a la sala de audiencias (en Corrientes Capital). Todas estas situaciones fueron denunciadas a organismos de derechos humanos e informados a la propia Fiscalía. 
indicaba que se retirasen o amenazaba desalojar la sala frente a cualquier expresión del público.

Finalmente, hay cuestiones notables que deberán ser pensadas con mayor profundidad en análisis posteriores y que tienen que ver con el modo en que ese escenario judicial tuvo la capacidad de evidenciar un entramado de poder vigente que expresa relaciones de subordinación de clase, género y origen étnico. ${ }^{52}$ Por un lado, reafirmamos la importancia de realizar un análisis de clase para dar cuenta de las formas que adquirió el proceso judicial, las distancias y desigualdades en las posiciones estructurales de cada uno de los participantes, ya sean víctimas y/o familiares, imputados y/o actores judiciales. Una gran parte de los testigos declarantes eran trabajadores o familiares, muchos de ellos analfabetos/as: en algunos casos habían tenido que abandonar su ciudad para lograr conseguir trabajo, otros habían continuado trabajando, enfrentando diversas dificultades, en situaciones laborales precarias e inestables, y difícilmente habían logrado perder el temor de aquellos años.

Aún con los pocos funcionarios judiciales que pretendían que los testimonios se desarrollaran como actos reparatorios en la vida de las personas, fueron expresas las dificultades de diálogo, la incomprensión de expresiones idiomáticas y modismos, develadas por las preguntas y repreguntas de los funcionarios, ${ }^{53}$ la ignorancia respecto de formas de trabajo y de vida, y sobre todo la imposibilidad de poder escuchar en las respuestas de las y los testigos (muchos iletrados), el eco de las distancias profundas entre quienes están de un lado del estrado y quienes están del otro, así como las relaciones de poder y dominación que irremediablemente permean y condicionan estos escenarios.

Otra reflexión necesaria y pendiente tiene que ver con el contexto fuertemente generizado del escenario judicial. La presencia masculina era potencialmente autoritaria y temible, desde el presidente del Tribunal, las fuerzas militares y policiales armadas dentro y fuera de la sala, hasta el acusado de perpetrar o ser partícipe de los crímenes, que en este caso, además, conservaba una posición social y económica prominente en la localidad. Muchas de las testigos mujeres eran las esposas e hijas de obreros presos o desaparecidos. En sus testimonios expresaban situaciones muy diversas pero que denotaban su rol subordinado: una de ellas había trabajado junto a su

52 Carlo Ginzburg, El queso y los gusanos (Barcelona: Atajos, 1999).

53 Uno de estos funcionarios, en una conversación en la que se le expresó estas dificultades evidentes de diálogo, afirmó vehementemente que "no podía bajar más su nivel” para hacer las preguntas, a la vez que dijo “¿querés que aprenda guaraní para que me entiendan?”, lo que también nos lleva a la necesidad de repensar en futuros análisis las relaciones interétnicas y su relación con las estructuras de dominación actual. 
marido desaparecido en la tarefa ${ }^{54} \sin$ que su trabajo productivo hubiera sido reconocido como tal por los patrones. Otra, luego de la desaparición de su marido, había quedado sola a cargo de sus hijos, y "Don Adolfo" le había ofrecido un puesto de trabajo que, por supuesto, había tenido que aceptar. Una hija de un obrero que había estado preso contó que, al ser detenido su padre y su marido, ambos dirigentes sindicales, un contratista con responsabilidades en la empresa le ofreció su "protección”, la cual-según dejó entrever- significaba tener relaciones sexuales. Debido a esto tuvo que escapar a Buenos Aires. Finalmente, el origen étnico está latente en cada testimonio y en la región remite a la colonización y el reclutamiento forzado de mano de obra originaria.

En la actualidad, y luego de esta absolución, el Ministerio Público Fiscal en junio de 2019 presentó una denuncia para que se investigue la responsabilidad empresarial en los delitos cometidos contra los trabajadores y en especial la responsabilidad de Adolfo Navajas Artaza. Ese mismo mes se presentó un pedido de requerimiento de instrucción penal contra Navajas Artaza por considerarlo responsable de la privación ilegítima de la libertad de seis trabajadores de su establecimiento. Por otro lado, a fines del año 2020 la Secretaría de Derechos Humanos de la Nación se presentó como querellante en la causa: se espera no sufra dilación, considerando que el imputado tiene 93 años de edad.

\section{Conclusiones}

En este artículo abordamos casos de diferentes empresas agroindustriales radicadas en las regiones del noroeste y noreste argentino, para poder analizar no solo las responsabilidades empresariales en los delitos de lesa humanidad cometidos contra trabajadores durante el terrorismo de Estado, especialmente durante la última dictadura, sino también las posibilidades de juzgar esas responsabilidades y las dificultades enfrentadas en cada uno de los casos. Tomamos los casos de tres ingenios azucareros, de las provincias de Jujuy y Tucumán, y una empresa yerbatera de la provincia de Corrientes.

54 Se denomina tarefa a la tarea de cortar yerba mate en el momento de la cosecha. Es una de las tareas menos valoradas del proceso productivo. Las condiciones de explotación de trabajadores/as tareferos/as en distintos momentos históricos han sido objeto de diversos análisis académicos. Ver Roberto Abinzano, "El Frente extractivista: una formación socioeconómica y espacial transfronteriza”, Cuadernos de la Frontera, 2 (2004); Delia Ramírez, "Van a enterrar hasta el último colonito”. Resistencias políticas, económicas y culturales de los colonos misioneros frente a la expansión y concentración agroindustrial (Tesis de maestría, Buenos Aires: Universidad Nacional de General Sarmiento/IDES, 2011). 
Desde un punto de vista estructural, en todos los casos estas empresas han diversificado sus producciones y han tenido un marcado desarrollo expansivo en sus territorios, siendo prominentes no solo en lo que atañe a la estructura económica-productiva, sino también en cuanto al régimen político y a la estructura social. Hay algunas características compartidas que es importante mencionar, para luego poder pensar en las particularidades.

Por un lado, es importante remarcar que todas las empresas analizadas tuvieron una fuerte expansión durante el siglo XX. Si bien en todos los casos se desarrollaron alrededor de una actividad preponderante, fueron diversificando su producción de la mano de un control territorial e incidiendo hasta la actualidad de manera significativa en las economías regionales. Por otro lado, la presencia empresarial se expresó en múltiples ámbitos de la vida social que atañen tanto al consumo y distribución de bienes y servicios como a actividades recreativas y educativas, generando así relaciones de dependencia y control social. Asimismo, en todos los casos se evidenciaron vínculos muy estrechos entre el poder político y militar en la región, fortalecidos en esa coyuntura pero forjados en un largo proceso histórico. Del mismo modo, directa o indirectamente, comenzaron a financiar y fueron parte constitutiva de las fuerzas públicas encargadas del control, la vigilancia y la represión.

Con respecto a la fuerza de trabajo utilizada en los procesos productivos, se trata preponderantemente de poblaciones nativas originarias y criollas y, en algunas regiones como en el nordeste argentino, población de origen inmigrante, llegada al país al calor de las políticas de inmigración. En todos los casos se comprobó la existencia de deficientes condiciones de trabajo, vivienda y salud; en muchos casos el reclutamiento de la fuerza de trabajo se realizó originalmente a fines del siglo XIX y principios del siglo XX de manera forzosa y/o a partir de la desposesión de tierras. Entre las características sobresalientes podemos mencionar salarios penosos, que en muchos casos se hacían efectivos por medio de vales para la compra de alimentos, inestabilidad laboral, vinculada en muchos casos a la estacionalidad del empleo, extensas jornadas de trabajo, importantes problemas de salud vinculados al proceso productivo, muy deficientes o nulas posibilidades de atención médica, hacinamiento y condiciones habitacionales muy deficientes. Dentro del colectivo laboral se evidenciaron diferencias entre las condiciones de las y los trabajadores rurales (del surco, del campo o del monte) y las condiciones de quienes trabajaban en el sector industrial, siendo el trabajo rural el de peores condiciones. Sin embargo, todos y todas las trabajadoras estuvieron sometidas a la violencia física y simbólica que supone la explotación laboral extrema y el dominio económico, político y social de estas importantes estructuras empresarias. Un aspecto que no hemos profundizado en este artículo, pero que consideramos requiere un 
abordaje específico y en profundidad, tiene que ver con las formas en que fueron afectadas diferencialmente las mujeres.

A pesar de estos condicionamientos, la organización sindical fue muy relevante. En el caso de los trabajadores de la agroindustria azucarera tucumana, tuvo un lugar central la organización en la FOTIA, que representaba tanto a los trabajadores de fábrica como a los rurales, potenciando las manifestaciones y acciones. Durante el período analizado, se eliminó aproximadamente la mitad de los puestos de trabajo en la agroindustria azucarera, junto a un proceso de concentración monopólica de la producción y la incorporación de nueva maquinaria tanto en la fábrica como en el campo, que beneficiaron altamente a los ingenios aquí analizados. Esto fue resistido por los trabajadores a través de diferentes medidas de lucha.

En el caso del Ingenio Ledesma, en Jujuy, puede rastrearse un proceso de organización sindical desde inicios de los años sesenta, con el surgimiento del Sindicato SOEAIL. Sin embargo, a inicios de los años setenta esa estructura sindical era considerada por muchos trabajadores como beneficiosa para la empresa: a partir de allí comenzó un proceso de organización sindical de base que culminó con la recuperación del sindicato. Por otro lado, a nivel político, la elección de Aredez como intendente permitió una serie de cambios que podían llegar a transformar la estructura de poder local.

Si bien en el caso de los trabajadores de la empresa "Las Marías" el proceso de organización fue posterior, llegó a conformarse una organización que comenzó a enfrentar a la empresa y plantear demandas históricas a partir de las cuales se unificaron los trabajadores rurales y los de la industria, generando una fuerte preocupación empresarial ya que además en la región comenzaban a tener una fuerte incidencia no solo organizaciones políticomilitares, sino experiencias como las de las ligas agrarias y movimientos católicos con ideas tercermundistas.

En los casos analizados, el proceso por Memoria, Verdad y Justicia desde el retorno de la democracia avanzó con serias dificultades y con distintos resultados y posibilidades respecto al juzgamiento de los responsables civiles. En el marco de un proceso marcado por avances y retrocesos, recién a partir de la anulación de las "leyes de impunidad", con ratificación por parte de la Corte Suprema de Justicia de la Nación en 2005, se logró reabrir procesos de juzgamiento de los responsables. Inicialmente se juzgó a los responsables militares en causas que tenían como ejes operativos represivos específicos o la actuación de determinadas fuerzas militares en las regiones. Como puede verse en estos casos, a pesar de las dificultades, se están llevando a cabo procesos judiciales que han sido muy importantes para las víctimas, sus familiares, las comunidades y la sociedad en general. Estos han permitido 
develar experiencias ocultas, negadas o estigmatizadas, y han posibilitado avanzar en el conocimiento de la verdad, en las atrocidades cometidas sobre las víctimas y sus familias así como en los efectos del disciplinamiento sobre todo el tejido social. Asimismo, han podido sustanciar la existencia de circuitos represivos, de centros clandestinos de detención en espacios hasta ahora desconocidos.

Al mismo tiempo, lo cierto es que la administración de justicia ha mostrado serias dificultades y trabas. Estas expresan connivencias entre el poder económico, político y judicial, que por medio de diversas estrategias han logrado dilatar el inicio de los juicios, diluir responsabilidades y/o permitir que el paso de los años impida llevar al estrado a los responsables. En otros casos, y a pesar de que fiscales y querellas han aportado pruebas suficientes, se han fallado "faltas de mérito", como en el caso de los imputados del Ingenio Fronterita y los del Ingenio Ledesma, o absoluciones, como en el caso de los imputados empresariales en la causa conocida como "Las Marías". Pese a estas constantes dificultades, los colectivos de sobrevivientes, familiares de las víctimas, abogados y organismos comprometidos han encontrado maneras de continuar buscando justicia a partir de apelaciones, recurriendo a instancias judiciales superiores o a partir de la apertura de nuevas causas.

Si bien muchos de estos procesos aún se encuentran abiertos, sería importante profundizar en las relaciones existentes entre las múltiples trabas y dilaciones de los procesos judiciales y las estructuras de poder aún vigentes a nivel territorial y económico en estas regiones. Estos procesos judiciales con múltiples reveses y dilaciones culminan en la mayor parte de los casos con la impunidad e imposibilidad de justicia para las víctimas, ya sea por las absoluciones, faltas de mérito o por el fallecimiento de posibles imputados así como de testigos que habrían sido claves para lograr las condenas. En la posibilidad de condena de personas que han sido y aún son de una importancia mayor en estas localidades, descansa la posibilidad de poner en cuestión las estructuras de dominación vigentes y llevar indefectiblemente a la posibilidad de que poblaciones que han vivido bajo el signo del silencio y la injusticia puedan verse resarcidas, reconocidas y en cierta medida vean reparados, aunque nunca cabalmente, los daños pasados y sus consecuencias en el presente. 
Title: Corporate Responsibility during the Last Argentine Dictatorship: Studies of Agro-industrial Companies in the Northwest and Northeast Regions (1974-1983)

Abstract: This article analyzes the investigation and prosecution of cases of corporate responsibility in crimes against humanity during the last dictatorship in Argentina (1976-1983). It studies four cases of agro-industrial companies: two sugar mills located in the provinces of Tucumán (La Fronterita and Concepción mills) and another in Jujuy (Ledesma mill), and a tea and yerba mate company in the province of Corrientes (Las Marías). The article stresses that all these cases include not only factory work but also rural work, characterized by a greater precariousness of labor relations and greater exploitation. It emphasizes the potential of these studies, but also points out the obstacles and limitations of these processes of Memory, Truth and Justice due to the strong corporate power and the difficulties of labor and union organization.

Keywords: Argentine dictatorship (1976-1983), agro-industrial activities, corporate responsibility, human rights violations, process of Memory Truth and Justice

Titulo: Responsabilidade corporativa na última ditadura argentina: contribuições de casos de empresas agroindustriais nas regiões Noroeste e Nordeste (1974-1983)

Resumo: Este artigo analisa os processos de investigação e de processo judicial de casos de responsabilidade corporativa em crimes contra a humanidade durante a última ditadura na Argentina (1976-1983). Em particular, estuda quatro casos de empresas agroindustriais: dois engenhos de açúcar localizados nas províncias de Tucumán (La Fronterita e Concepción) e outro em Jujuy (Ledesma), e uma empresa de chá e erva-mate na província de Corrientes (Las Marías). O artigo sublinha que todos estes casos incluem não apenas o trabalho de fábrica, mas também o trabalho rural, caracterizado por uma maior precariedade das relações de trabalho e uma maior exploração. $\mathrm{O}$ potencial desses estudos é enfatizado, mas também os obstáculos e limitações desses processos de Memória, Verdade e Justiça, devido ao forte poder empresarial e às dificuldades de organização dos trabalhadores e sindicatos.

Palavras-chave: ditadura argentina (1976-1983), atividades do agronegócio, responsabilidade corporativa, crimes contra a humanidade, processo de Memória, Verdade e Justiça 